\title{
Discussion of Management Innovation of Green Construction
}

\author{
Min Jing ${ }^{1}$, Jiangtao Kong ${ }^{2}$ \\ ${ }^{1}$ School of Civil Engineering, Nanyang Institute of Technology, Nanyang Henan, 473000, China \\ ${ }^{2}$ Nanyang Institute of Architectural Design, Nanyang Henan, 473000, China
}

Keywords: Green construction, Management innovation, Method.

\begin{abstract}
Starting from construction enterprise, this article studies management innovation of green construction during construction process, mainly including significance, current situation and content of management innovation of green construction as well as suggestions to improve management innovation efficiency of green construction.
\end{abstract}

\section{Introduction}

The construction industry is the biggest source of greenhouse gas emission. The construction energy consumption occupies $1 / 3$ of global total energy consumption. About $60 \%$ energy consumption is related to construction industry. Construction energy consumption of China has occupied $30 \%$ of total energy consumption. Improving building efficiency has become the important channel to realize energy conservation and emission reduction and environmental enhancement. Actively optimizing and innovating construction management of green architecture is of great significance to realize energy conservation and consumption reduction in construction industry.

\section{Significance of management innovation of green construction}

The green construction defined in Guide Rules of Green Construction refers to realize four savings and one environmental protection (energy saving, land saving, water saving, material saving and environmental protection) under the precondition of basic requirements such as guaranteeing quality, safety, etc. during engineering construction. [2] Green construction idea is a kind of innovation which makes construction process more efficient and secure, with environmental protection, energy-saving and cost-reducing. Green construction idea conforms to the idea of sustainable development, the requirement of balanced development of ecological environment. Only when enterprises actively study the secure and feasible green construction management method can they guarantee and keep improving construction quality of green architectures.

\section{Current situation of management innovation of green construction}

Green construction management is the umbrella name for the series of construction management ideas of new engineering constructions with green construction technology as fundamental idea. The major performance is to pay attention to sufficiently and rationally use all kinds of materials, energy and resources during construction process, recycle and circulate as far as possible, reduce unnecessary waste, save resources, guarantee progress and quality of works, pay attention to protect circumjacent ecological environment and reduce the most harms to environment. Construction management of green architecture reflects sustainable Scientific Outlook on Development and the people oriented idea, which is also the most impetus for construction enterprises to promote market comprehensive competitive power and get long-term development [3]. (1) Planning and implementation of energy-saving target of project: in order to guarantee the realization of goal and, it 
should set up working group and the first principal, specific tasks making division of labor according to functions and realizing specially-assigned person responsibility. To avoid conflict of each profession and type of work, it should rationally arrange construction connection according to site and inspect each subsection of progress condition of implementation and goal of green construction economic measures. (2) How to choose the method of green construction. During construction process, it should reduce energy loss from such aspects as construction technologies, techniques, personnel management, etc. actively study and choose construction technology going green and environmental protection, select green, natural and environment friendly energy and meanwhile reinforce people's energy conservation and environment protection idea to make them pay attention to standard operation and not waste in construction process, further realizing the purpose of saving energy. (3) Management of materials in construction site: material management is the key contents of construction management of green architecture. Management principles are to reduce material waste, environmental disruption and pollution by intensifying material management and meanwhile enhance efficiency of construction to guarantee construction quality. Main project management method is to set up materials handling department of engineering materials for management of choosing, keeping, use registration and classification collection of materials to effectively manage engineering materials from choosing, using to recycling, provide particular, real and comprehensive data for finance department to account material cost, effectively control engineering construction cost and reduce waste of construction material as far as possible. (4)Management of water resource in construction site. Intensifying water resource management is also the important contents in construction management of green architecture, mainly by rationally planning water use in construction process and realizing the goal of water saving with a series of water saving technologies. For example, when choosing running-water mechanical equipment, it could give priority to type with better water-saving performance and meanwhile related personnel should regularly check the water-use equipment in construction site to find problems such as dripping, leakage, etc. in time and adopt treatment measures to reduce unnecessary waste. (5) Management of environmental protection: during construction process, it should reduce such solid construction waste as concrete, brick, tile, mortar, stone, sand, etc. as far as possible to reduce environmental pollution, as well as the direct pollution to environment or people by dust, sewage, light, noise, etc.

\section{Contents of management innovation of green construction}

\section{Idea innovation}

In order to realize innovation of construction management of green architecture, the first thing that enterprises should do is to innovate construction management idea and change the idea of senior managers. Managers must realize the significance of innovation and pay enough attention, giving support to career plan and expenditure, increasing investment of such aspects as talent cultivation, technology import, etc. and meanwhile actively improve thinking model of business management. The most effective method to realize this is to actively introduce and cultivate all kinds of new-type talents. Firstly, enterprise needs to cultivate talents of engineering design, construction, financial management, etc. such as adjusting talent recruitment plan, attracting social talents, reinforcing cooperation with colleges and universities and thus cultivating high-quality utility-type talents with high professional competence. Secondly, it should intensify comprehensive business training of employees of the enterprises, regularly organize some activities as professional skill learning, skill competition, professional skill examine, etc. promote employees' professional skill and profession culture and thus promote overall professional ability and qualification of enterprises' employees to enhance enterprise comprehensive abilities. Thirdly, it should pay attention to market change, adjust enterprise talent structure in time according to market change laws and market requirement, establish innovation-type construction management mode with market requirement and enhance management efficiency. Fourthly, it should increase opportunities of engaging in advanced studies for employees of the enterprises, encourage them to keep continuous learning, promote ego and working enthusiasm 
and effectively motivate their innovative potency. The enterprise managers are the leaders of enterprise development. Only when the managers change idea and innovate concept could they indeed drive the entire personnel's idea change and promote each department and employees to propose constructive idea to work in their own scope of official duty driven by innovative thinking and thus to improve work efficiency and quality.

\section{Institutional innovation}

In order to realize innovation of construction management of green architecture, the most important is to innovate relevant management system. Innovating management system should gear to actual construction situation, accord with construction requirement and guarantee feasibility and effectiveness of new system. Firstly, it should make green construction management plan, mainly including site operation, surroundings environmental management, emergency processing of emergencies, etc. paying attention to management of details and reducing load of construction technology to construction technology. For example, as for energy management, except to make corresponding management system to energy species select, use procedure, etc. it could also get down into requirement of using energy in each procedure. For example, as to power utilization, it must pull electric wires according to practical construction requirement, inspect whether power supply is close or not of correlated electric equipment when construction suspending or finishing and avoid waste caused by power consumption under inactive state of equipment. As for water resource management, except to make effective water saving system, it should make water resource protecting measures, for example, household refuse and construction waste should be gathered for sorting treatment, rather than easily throw about or even pour into pool to cause water resource pollution. It should manage water draining in construction site, rather than discharge sewage with oil paint, metal, etc to soil or water areas, construct sewage recycle pool and adopt corresponding treatment measure to dispose hazardous substance in natural environment. It could also discharge into reutilization wastewater pool and those can not be reutilized should discharge into drainage channel to protect water resources and land source for less pollution.

\section{Construction quality management innovation}

Construction enterprise should actively innovate construction quality management, enhance engineering construction quality and guarantee performance and fame of enterprises. Firstly, to carry out responsibility system. It would change the situation that each subproject with many principals, just appoint one main principal, then add more group leaders according to specific situation such as construction scale, constructors quantity, etc. to in charge of management of checking-in, security control, etc. of each construction group. Everyone has responsibility and make sure rights and liabilities of each department and person so that it could find the person in charge in time when there is quality problem, to avoid buck-passing and improve sense of duty to provide important guarantee to construction quality. Secondly, To make construction process standard, especially in the constructional engineering of short time limit, it should guarantee standardability of construction process and avoid such situation of cutting short part processes. Thirdly, to intensify construction supervision, including executive condition of security arrangement, construction operation specification condition, service condition of mechanical equipment and material, etc. At the same time, it should intensify personnel knowledge education of safety construction, standard construction, etc. to avoid such behaviors of cheating on workmanship and materials, operation against rules, etc. of part persons because of lacking safety awareness or green construction idea. Fourthly, to improve initiative and perspectiveness of construction quality management. During construction technology, most quality problems would be discovered after finishing to check and accept or coming into use, and then adopt corresponding treatment measures such as improvement, reworking, etc. the construction quality management rather lags behind, which not only increase investment of such costs of time, capital, manpower, etc. but also enlarge influenced range and harm of quality problem. Thus, it should strictly implement construction quality management before, during or after 
construction, improve initiative of construction quality management and check hidden danger of quality problem in time.

\section{Technological innovation}

Carrying out technological innovation is the core content of management innovation of green construction, including construction technique, energy-saving technology, technology of reducing noise, etc. As for construction technique, it should improve engineering design technique, for example, during building construction, it should rationally design allocation plan of building when the land is limited and reduce floor space to the greatest extent under such premise of enough lighting, ventilation, interior space, etc. to effectively improve land resource utilization rate and increase land use for greening. As for energy-saving technology, it should pay attention to adjust such aspects as mechanical equipment selection, power parameters setting, etc. to reach optimal energy-saving and cost-reducing effect under the precondition of guaranteeing efficiency and quality of construction. During building operations, noise pollution is also the important environmental pollution factor, whose noise sources are mainly each big construction instrument, camion, etc. causing severe influence to residents' daily life such as working, studying, resting, etc. Thus it should install silencers to reduce noise sources and meanwhile adopt multiple noise attenuating measures to enhance noise attenuation effect. It should build sound insulation walls with high-performance sound absorption or sound insulating materials around construction site, adopt silencers and avoid night work to reduce the influence of noise.

\section{Suggestions to improve efficiency of management innovation of green construction}

\section{To increase application of information technology in green construction management}

Information construction is also intelligence construction, one of the effective methods for developed countries to adopt green construction. It is the green construction method to do construction management by real-time quantification and dynamic condition of dynamic parameter (information and job machinery in construction site). It applies many state-of-the-art facilities (such as teleautomatics, global positioning system, electronic sensor, full angle of view vidicon, etc.) and matched corresponding software to proceed construction machinery construction management, labor management, operations management, production management, etc. and could choose optimum equipment quantity and variety for real-time adjustment, finishing task object by fewer investment and realizing goals of environmental protection, high efficiency and low consumption. This method has been applied to projects with advanced management conditions in China and get better effect, which deserves generalization. It works out such problems as big construction project area, complex topography and large amount of staff, etc. for example, as for construction technology, it could use GPS to pinpoint and solve problem of inaccurate measurement. By dynamically and intuitively monitoring and recording such production status as construction progress, safety civilization, etc. it could timely discover and avoid potential safety hazard, acquire image data to improve work efficiency.

\section{To develop industrialized construction}

Industrialized construction is a kind of intensified and sustainable form of construction work evolved by housing industrialization in developed countries, which regard multiple and different kinds of buildings as industrial products, adopt unitive structural style, design a set of standard modular component and produce large batch in a factory with advanced technology, then implementing installation of high degree of mechanization. Such industrialized modular residence mainly adopts steel or wooded skeleton structure, floor and walls with composite materials and finishes assembly of box-shaped structure in production line, with integrated kitchen, stairs, doors and windows, toilets, etc. all installing into a box. Roofs are also made in factory, which all greatly reduce work in the site and reflect spirit of green construction. ${ }^{[5]}$ It could better drive social and economic development. 
Such industrialized construction needs strong scientific research and exploitation strength as technical support, which is at development phase at home and needs more time for popularization and application.

\section{Conclusion}

Green construction management is the new type construction management mode with green construction idea as guidance, energy-saving and cost-reducing as well as pollution abatement as goal. Under the background of increasingly advanced engineering technology and furious market competition, actively innovating the green construction management is of great significance to the development of construction industry.

\section{References}

[1] Chen Xiaolong, Liu Xiaobing, Influence of Transaction Cost to Green Architecture Development Decision of Developers, journal of Tongji University (natural science edition) ,2015 (01: 153.

[2] Wang Junxiang, Study on Sustainable Development and Green Construction, Shandong University: architectural and civil engineering college 2012.3.

[3] Zhou Wenlong, Study of Construction Management Based on Green Construction Idea, interval construction materials, 2015 (22: 97, 100. 